\title{
EQUILÍBRIO REFLEXIVO AMPLO E A REVISIBILIDADE DAS CRENÇAS MORAIS
}

\author{
WIDE REFLECTIVE EQUILIBRIUM AND THE REVISIBILITY OF \\ MORAL BELIEFS
}

\author{
TIARAJU M. ANDREAZZA ${ }^{1}$ \\ (Universidade do Vale do Rio dos Sinos, Brasil)
}

\begin{abstract}
RESUMO
O método do equilíbrio reflexivo amplo é um modelo epistemológico em filosofia moral cuja grande virtude é a sua capacidade para acomodar o que pode ser chamada de uma atitude revisionista: nenhuma crença moral é imune à revisão e qualquer crença moral está sujeita a ser descartada se se mostrar incoerente com novas informações ou com um novo e melhor sistema coerente de crenças. Por definir a justificação como uma questão de ajuste mútuo entre crenças, alguns filósofos interpretam que o equilíbrio reflexivo amplo deve ser entendido como um método coerentista de justificação e que apenas uma interpretação não-fundacionalista do método poderia acomodar a atitude revisionista. O objetivo deste ensaio é argumentar contra essas duas teses. Será proposta uma interpretação fundacionalista para o equilíbrio reflexivo amplo que é claramente revisionista. Será argumentado, contra a interpretação coerentista, que o equilíbrio reflexivo atribui um status epistêmico especial aos juízos morais ponderados afirmados com um alto nível de comprometimento, e que apenas uma interpretação fundacionalista do método está equipada para explicar essa sua característica.

Palavras-chave: Equilíbrio Reflexivo Amplo. Revisionismo. Coerentismo. Fundacionalismo. Juízos Morais Ponderados.
\end{abstract}

\begin{abstract}
The method of wide reflective equilibrium is an epistemological model in moral philosophy whose biggest virtue is its ability to embrace what could be called a revisionist attitude: there are no moral beliefs immune to revision and any moral belief can be dropped if so required by new information or a new and better coherent system. Considering that for the reflective equilibrium justification is a matter of mutual adjustment of many beliefs, some philosophers argue that the wide reflective equilibrium is better interpreted as an coherentist method of justification and that only such a nonfoundationalist interpretation could accommodate the revisionist attitude. The aim of this essay is to argue against these two claims. Thus, a foundationalist and revisionist interpretation of the reflective equilibrium will be proposed. It will be argued, against the coherentist interpretation, that the reflective equilibrium credits a special epistemic status to the considered moral judgments affirmed with a higher level of commitment, and that only a foundationalist interpretation could explain this feature of the method.

Key-words: Wide Reflective Equilibrium. Revisionist Attitude. Coherentism. Foundationalism. Considered Moral Judgments.
\end{abstract}

Muitos filósofos tomam o método do equilíbrio reflexivo amplo (wide reflective equilibrium, ERA daqui em diante) como o exemplo de um modelo epistemológico em filosofia moral cuja grande virtude é a capacidade para acomodar o que podemos chamar de uma atitude revisionista: nenhuma crença moral é imune à revisão e qualquer crença moral 
está sujeita a ser descartada se se mostrar incoerente com novas informações ou com um novo sistema de crenças morais ${ }^{2}$. A atratividade do revisionismo consiste em afastar o dogmatismo ao promover a ideia de um agente moral como alguém que deve estar sempre disposto a revisar as suas crenças e a considerar com atenção outros pontos de vista diferentes do seu.

Métodos fundacionalistas de justificação defendem que algumas de nossas crenças morais são justificadas não-inferencialmente, isto é, elas não são justificadas em função da sua relação com outras crenças, mas porque são autoevidentes (como são, alguém poderia argumentar, as verdades matemáticas e lógicas) ou justificadas por algum estado que não é uma crença (como uma emoção, intuição ou percepção). Alguns coerentistas acreditam que o fundacionalismo não é capaz de acomodar um nível satisfatório de revisionismo, e que por isso o ERA tem de ser interpretado como um método coerentista de justificação (DANIELS, 1996, p. 26-28). Por exemplo, se eu alego que a escravidão é injusta porque eu 'vejo', 'intuo' ou 'só sei que esse é o caso', então nenhuma outra consideração que eu ou outra pessoa puder oferecer a seu favor ou contra poderia aumentar ou reduzir a sua credibilidade epistêmica para mim. Alguns coerentistas sugerem que o fundacionalismo não é inclusive capaz de permitir que nossas crenças morais básicas sejam revisadas à luz de crenças não-morais, justamente o que o ERA exige (SAYRE-MCCORD, 2007, p. 124).

Há duas alegações fundamentais envolvidas nesse raciocínio: a primeira é a de que o equilíbrio reflexivo amplo é um método coerentista e a segunda é a de que apenas o coerentismo pode acomodar a atitude revisionista. O objetivo deste artigo é defender que ambas as alegações são inconvincentes. Como a falsidade da segunda é hoje um ponto incontroverso entre epistemólogos, reservarei o maior número de páginas à discussão da primeira alegação. Pretendo oferecer uma interpretação fundacionalista para o equilíbrio reflexivo amplo que é claramente revisionista. Na seção seguinte apresentarei o que devemos entender por ERA. Na medida em que a versão mais sofisticada do ERA pode ser encontrada em Rawls, partirei dos seus comentários sobre o método. Na segunda parte analisarei a controvérsia fundacionalismo vs coerentismo na literatura sobre o ERA, oferecendo um argumento contra a interpretação coerentista. Por fim, encerrarei com algumas observações a respeito do status das crenças não-inferencialmente justificadas, tal como elas podem ser entendidas por uma interpretação fundacionalista do ERA.

\section{O método do equilíbrio reflexivo amplo}


Rawls afirmou que se as pessoas "descartarem alguns juízos e revisarem outros", e se elas se valerem da "persuasão intuitiva de uns para avaliar a plausibilidade de outros", elas estarão em equilíbrio reflexivo (RAWLS, 1975, p. 7-8). É um estado de equilíbrio porque crenças e desejos estão em uma relação de "ajuste mútuo" e assim estão, para adotar a expressão de Smith, sistematicamente justificados (SMITH, 1994, p. 159), e é um estado reflexivo porque é o indivíduo, via reflexão, quem o alcança. Note que há uma certa ambiguidade no uso do nome "equilíbrio reflexivo". Em muitos casos o termo é usado para descrever um certo estado mental do indivíduo - um estado composto por um sistema de crenças que estão relacionadas de uma determinada maneira e que é aceito pelo indivíduo ${ }^{3}$. É isso que Rawls tem em mente quando ele afirma que a sua concepção de justiça descreve o que alguém afirmaria se estivesse em equilíbrio reflexivo (RAWLS, 1999, p. 41-43). Algumas vezes Rawls afirma que "o equilíbrio reflexivo requer apenas que o agente faça essas revisões com convicção e confiança” (RAWLS, 1975, p. 8). É claro que o método não figura nessa sentença como uma descrição de um estado mental, mas, ao invés, aponta para uma concepção de como alguém deve proceder para decidir da melhor maneira possível que teoria da justiça aceitar, o que acreditar e como agir ${ }^{4}$. No restante deste ensaio reservarei a expressão "equilíbrio reflexivo" para a ideia de procedimento e "apropriadamente reflexivo" para o seu resultado.

A melhor maneira de apresentar o ERA é sumarizá-lo em um conjunto de passos que define o que é uma reflexão apropriada (due reflection, nas palavras de Rawls (RAWLS, 1993, p. 8) ${ }^{5}$. Ao começar a refletir, o primeiro passo do utilizador do ERA, vou chamá-lo de $S$, é desconsiderar todos os seus juízos que não são ponderados (considered), isto é, todos os juízos realizados em circunstâncias desfavoráveis ao julgamento, como quando se está emocionalmente abalado, demasiadamente focado no autointeresse (por exemplo, ignore os seus juízos sobre o justo valor de uma multa de trânsito se esse juízo é realizado no momento em que você se deu conta de que acabou de ser multado), sob a influência de coerção etc (RAWLS, 1999, p. 42). $S$ também deve abandonar os desejos causados por esses juízos, bem como qualquer outro elemento do seu sistema de crenças que dependa causalmente deles. O raciocínio é que esses juízos não representam o verdadeiro senso de justiça de $S$ e não seriam sustentados se essas circunstâncias desfavoráveis não estivessem presentes. São, por assim dizer, recursos normativos irrelevantes.

Tendo selecionado o que conta como ponderado, no segundo passo $S$ deve identificar preliminarmente quais são os pontos fixos provisórios do seu sistema de crenças. Como ethic@- Florianópolis, Santa Catarina, Brasil, v. 14, n. 3, p. 473 - 489. Dez. 2015. 
descritos por Rawls, se tratam de crenças que $S$ sente com certeza que são verdadeiras e que está indisposto a rejeitar (RAWLS, 1999, p. 17). Como proponho, a diferença entre os pontos fixos e os não-fixos está no nível de comprometimento ou confiança com que são sustentados. Por exemplo, em geral depositamos muito mais confiança nas crenças de que "a escravidão é injusta", "devemos evitar a dor", "ninguém deve insultar uma pessoa pela sua cor" e "seria errado colocar fogo no gato por diversão" do que depositamos nas crenças de que "nossa sociedade deve ser regulada de acordo com uma concepção liberal de justiça”, "devemos permitir a eutanásia involuntária" e "uma mulher tem o direito de abortar depois dos três meses, se ela quiser". Os juízos do primeiro grupo nós sentimos com certeza ("feel sure", nas palavras de Rawls) que são corretos, já os juízos do segundo grupo admitimos (ou pelo menos muitos de nós) que podem ser falsos porque os aceitamos com muito menos "confiança" (“much less assurance"). Os juízos do primeiro grupo são mais estáveis, pois perduraram ao longo da vida de uma pessoa não importa se ela mude de país, religião, classe social ou visão política. Juízos do segundo grupo são muito mais instáveis e podem - provavelmente irão ser modificados ou inteiramente recusados dependendo das circunstâncias contingentes da vida. Como são normativamente relevantes, os juízos ponderados não-fixos não devem ser descartados, apenas deixados de lado por enquanto.

Tendo identificado quais são os seus pontos fixos provisórios, no terceiro passo $S$ deve buscar por considerações gerais que os expliquem. Por exemplo, $S$ pode chegar à conclusão de que está indisposto a descartar uma variedade de juízos, tem uma variedade de desejos, planos e intenções, porque considera que é errado violar a igualdade de direitos e deveres morais entre as pessoas e que ninguém deve provocar sofrimento para outras pessoas a não ser que esse sofrimento seja necessário para evitar um sofrimento maior. Rawls sempre cita dois juízos fixos (de repúdio à escravidão e de tolerância religiosa) e oferece como uma explicação desses juízos a aceitação da ideia mais geral de que todos os cidadãos devem ser tratados como livres e iguais. Como esse exemplo mostra, a ideia aqui é encontrar considerações de cunho mais geral e abstrato para explicar as razões pressupostas por trás da multiplicidade de juízos particulares realizados diariamente.

Se $S$ é uma pessoa normal, então ele se dará conta de que muitas das suas convicções morais ponderadas não-fixas são inexplicáveis. Isso acontece porque $S$ não encontrará nenhuma consideração geral, ou um conjunto de considerações, que explique todas as suas crenças morais. Ele precisará então resolver conflitos internos, ou, como poderíamos dizer, os 
seus problemas normativos. Esses conflitos podem ser de vários tipos. Pode ser entre duas ou mais crenças morais (em um momento $S$ considera imoral a tortura de terroristas para obter informações úteis, mas quando a segurança do seu país passa a estar em jogo, ele faz o juízo inverso), entre razões aceitas ( $S$ acredita que toda a vida humana deve ser respeitada e, ao mesmo tempo, acredita que alguém tem direitos apenas se segue a legislação do seu país), entre crenças e razões, e entre crenças morais e crenças não-morais ( $S$ sustenta que é correto realizar aborto até o quinto mês porque tem a crença, talvez equivocada, de que o feto até o quinto mês é incapaz de sentir dor). Nós ainda poderíamos falar de outros tipos de conflitos práticos como a fraqueza da vontade, hipocrisia e conflitos entre emoções e crenças (por exemplo, quando sabemos que não faz sentido sentir raiva da pessoa que faz a previsão do tempo, quando a previsão está errada).

O quarto passo é o momento em que $S$ deve eliminar, tanto quanto possível, esses conflitos. O seu objetivo é tentar se aproximar de um estado em que todos os elementos do seu sistema de crenças estão em uma relação de equilíbrio. Mas a prescrição aqui não é a de buscar coerência simplesmente. Coerência não nos informa muito. Suponha que minhas crenças $p_{1}$ e $p_{2}$ estejam em franca contradição com o meu sistema coerente de crenças. Eu tenho várias alternativas para me tornar coerente nesse caso: posso descartar $\mathrm{p}_{1}$, e $\mathrm{p}_{2}$, posso revisá-las, posso alterar o sistema de crenças para que ele comporte consistentemente $\mathrm{p}_{1}$ e $\mathrm{p}_{2}$, ou posso fazer modificações em $\mathrm{p}_{1}$ e $\mathrm{p}_{2}$ e no sistema de crenças ao mesmo tempo. Independentemente da minha escolha preferida, todas as opções me conduziriam ao estado de coerência, mas cada escolha produzirá um sistema coerente de crenças diferente. Qual é o melhor? Fazer essa pergunta é questionar como se deve obter coerência.

A resposta oferecida pelo ERA é a seguinte: $S$ deve utilizar as considerações mais gerais encontradas no passo três e utilizá-las como critérios de revisão. Em última análise, a finalidade é fazer com que todos os juízos estejam alinhados com as ideias subjacentes aos pontos fixos provisórios. Quando uma crença está em desacordo com essas ideias, significa que elas não refletem a verdadeira opinião de $S$ - ou, podemos dizer, a opinião de $S$ que não é apropriadamente reflexiva. Quando $\mathrm{S}$ falha em refletir adequadamente, ele falha em alcançar uma conclusão que corresponda aos seus comprometimentos realmente mais profundos e estáveis. Em outras palavras, S alcança uma conclusão baseada em uma crença que poderia ver como menos valorosa à luz do que mais ele acredita. Consequentemente, $\mathrm{S}$ alcança uma conclusão que não tem sucesso reflexivo. 
Se $S$ seguir os quatro passos corretamente, ele sustentará crenças e praticará ações que são apropriadamente reflexivas. Um indivíduo nesse estado fez o melhor uso possível dos seus recursos normativos, maximizando a coerência entre os seus comprometimentos e transferindo, tanto quanto é possível, a confiança com que sustenta juízos mais básicos e concretos para os juízos mais gerais e sofisticados. Confiança significa estabilidade reflexiva: $S$ agora está menos propenso a mudar de opinião, e dispõe de critérios para decidir o que fazer e pensar em momentos de incerteza. Isso não significa, porém, que o trabalho reflexivo tenha terminado. Sempre que $S$ tem uma nova experiência moral ou entra em contato com um novo conjunto de crenças, ele tem de considerar qual seria o resultado da inclusão desses novos elementos no seu sistema de crenças. Novas situações podem pressionar $S$ a reconsiderar. $S$ pode vir a ter um conflito interno, como quando lê um livro que o apresenta a uma nova perspectiva ou quando tem novas experiências de vida, ou, conforme destacado por Scanlon, o conflito pode ser externo, como quando $S$ se dá conta de que outra pessoa apropriadamente reflexiva afirma uma visão que é incompatível com a sua (SCANLON, 2014, p. 78-79). Se outra pessoa seguiu o ERA e alcançou um resultado diferente, $S$ terá de considerar por que isso aconteceu. Talvez o outro indivíduo tenha começado com diferentes juízos morais ponderados, ou tenha feito diferentes modificações nas etapas seguintes. Tudo isso deve ser fonte de dúvida para $S$ : ele não pode simplesmente negar a opinião do outro, ele deve tentar refutá-la e, se não conseguir, fazer os ajustes necessários para acomodá-la no seu próprio sistema de crenças. Por razões como essa que Rawls considerava o ERA como um processo sem fim, e o estado de apropriadamente reflexivo como um ideal do qual é possível se aproximar, mas não atingir (RAWLS, 1999, p. 43-44).

Se $S$ seguir os quatro passos - que, estou propondo, constituem o método do ERA ele sustentará crenças adequadamente refletidas. O que isso quer dizer? Aqueles que utilizaram o equilíbrio reflexivo ofereceram respostas distintas para essa questão. Já foi defendido ao longo dos últimos anos que elas são verdadeiras e constituem um tipo de conhecimento moral ${ }^{6}$. Mais modestamente, outros argumentaram que essas são crenças razoáveis ou racionais ${ }^{7}$. Independentemente de que alternativa resolvamos adotar, me parece claro que quando $S$ está em equilíbrio reflexivo, ele afirma o sistema de crenças que é, do seu ponto de vista, e no momento em questão, o mais justificado - isto é, aquele que em reflexão ele tem mais razões para afirmar ${ }^{8}$. 


\section{Coerentismo holista ou fundacionalismo moderado?}

$\mathrm{O}$ coerentismo e o fundacionalismo são duas teorias rivais que buscam descrever a estrutura do corpo de crenças de quem sustenta crenças justificadamente. Sendo assim, a questão presentemente relevante é esta: quando uma pessoa sustenta crenças justificadamente em ERA, a estrutura do seu corpo de crenças é linear, no sentido de que algumas crenças básicas fornecem o suporte para as demais (como em uma árvore que só se mantém em pé graças à solidez das suas raízes), ou é circular, em que cada crença deve o seu suporte ao seu ajuste com outras crenças, não havendo necessariamente uma parte mais fundamental (como uma teia de aranha ou uma pequena balsa)?

O ERA não permite a existência de crenças incorrigíveis e, como está no seu nome, defende a ideia básica de que a justificação depende de um certo equilíbrio entre crenças. Por isso qualquer variante infalibilista de fundacionalismo é claramente inadequada para servir de interpretação do método. O fundacionalismo em questão tem de ser moderado. A versão proposta por Audi pode cumprir esse papel:

Fundacionalismo moderado: para qualquer $S$ e qualquer $t$, (1) a estrutura do corpo de crenças justificadas de $S$ é, em $t$, fundacional no sentido de que a justificação de quaisquer crenças inferenciais justificadas (crenças não-fundacionais) de $S$ depende de uma ou mais crenças não-inferenciais justificadas (crenças fundacionais ou básicas) de $S$. A (2) justificação das crenças fundacionais de $S$ é anulável em t, se, em t, elas forem incoerentes com uma ou mais crenças de $S$ e (3) as crenças nãofundacionais não derivam toda a sua justificação das crenças fundacionais, mas derivam apenas o suficiente para que permaneçam justificadas se a justificação que elas obtêm de outras fontes for eliminada ${ }^{10}$.

Esse fundacionalismo é moderado ao menos por duas razões: (i) as crenças da superestrutura (crenças não-fundacionais) podem ser falsas mesmo quando as crenças fundacionais são verdadeiras (o link entre elas não é necessariamente dedutivo) e (ii) há espaço para que se descubra que, em um momento $t$ futuro, as crenças fundacionais conflitam ou com outras crenças fundacionais ou com crenças não-fundacionais adequadamente suportadas. A aquisição de novas crenças pode então anular a justificação das crenças fundacionais porque as crenças não-fundacionais não derivam toda a sua justificação das crenças fundacionais (é por isso que analogia com um prédio, em que qualquer drástica mudança nos andares inferiores pode significar a eclosão dos andares superiores, é inadequada para explicar a linearidade envolvida no fundacionalismo moderado. Se nós 
cortarmos corretamente as raízes de uma árvore, conseguimos gradualmente substituí-las sem precisar matá-la).

Em contraposição, o coerentismo holista proposta por Bonjour no início da sua carreira pode ser visto como o melhor rival. Nós podemos adotar a seguinte definição dessa posição, oferecida também por Audi:

\footnotetext{
Coerentismo holista: para qualquer $S$ e qualquer $t$, se $S$ possui crenças justificadas em $t$, então, em $t$, (1) elas são justificadas pela sua coerência com um sistema coerente de crenças de $S$; e (2) elas permanecem justificadas mesmo se (outras coisas sendo igual) a justificação que elas obtêm de outras fontes que não a coerência for eliminada (AUDI, 1993, p. 138) ${ }^{11}$.
}

Há três pontos centrais nessa definição. O primeiro é o caráter (i) holista ou não-linear da justificação: para que uma crença seja justificada, é necessário e suficiente que ela esteja em uma relação de suporte mútuo com um sistema de coerente de crenças. Como defende que a relação de suporte mútuo é suficiente para a justificação, o coerentista está comprometido com a tese de que a justificação de uma crença é sempre derivativa de outras. Se a justificação é derivativa, o coerentista também tem de aceitar que as crenças estão em uma relação de igualdade epistêmica, no sentido de que nenhuma crença desempenha um papel epistêmico privilegiado. O segundo elemento (ii) é a própria noção de coerência, que deve ser definida não apenas em termos de consistência lógica entre crenças, mas também em termos de relações probabilísticas e explanatórias. Uma terceira característica é a (iii) explicação do papel da noção de observação. Grosso modo, o coerentista defende que embora certas crenças sejam formadas não-inferencialmente ou "espontaneamente" em função de algum processo causal (como as crenças perceptivas), a sua justificação depende da sua relação com o conjunto de crenças de fundo já sustentado (BONJOUR, 2003, p. 45-53). Com isso o coerentista pode argumentar que a origem psicológica não-inferencial dos pontos fixos não implica uma justificação não-inferencial.

Não é sem motivo que o ERA é interpretado por muitos como coerentista. Ao descrever o método, Rawls alude repetidamente para um certo holismo. Por exemplo, comentando a justificação do conteúdo moral contido na sua teoria da justiça, ele escreve que é melhor tomá-lo como "estipulações razoáveis que devem ser eventualmente avaliadas por toda a teoria à qual elas pertencem" (RAWLS, 1999, p. 506). Esse tipo de afirmação sugere fortemente a característica (1) do coerentismo holístico, e por implicação a rejeição da 
característica (1) do fundacionalismo moderado. Rawls também defende que em questões de justificação não devemos operar com "verdades básicas": "eu não afirmo que os princípios de justiça propostos são verdades necessárias ou deriváveis de tais verdades. Uma concepção de justiça não pode ser deduzida de premissas autoevidentes" (RAWLS, 1999, p. 19). Passagens como essas parecem não deixar margem para dúvidas: para avaliar se uma crença é justificada é preciso considerar como ela se relaciona com outras crenças, sendo que essas outras crenças são a "teoria como um todo". Como Rawls concebe a justificação "como uma questão de suporte mútuo de muitas considerações, de tudo se ajustar em uma visão coerente" (RAWLS, 1999, p. 19), não parece sobrar espaço conceitual para a existência de crenças nãoinferencialmente justificadas, isto é, crenças cuja justificação não depende do suporte de muitas considerações. Afirmar que a justificação é simplesmente uma questão de apoio mútuo sugere a defesa da característica (2) do coerentismo holista: se a justificação que uma crença obtém de outras fontes for eliminada, mas ela ainda for coerente, ela ainda será justificada. A consequência fundamental dessa característica (2) é a tese de que a coerência é suficiente para a justificação.

Porém, há momentos em que Rawls descreve o ERA apontando para elementos fundacionalistas. Um desses elementos é a distinção entre os juízos morais ponderados fixos (fixed), que são aqueles juízos que sustentamos com alto nível de comprometimento, e os menos fixos, que são aqueles juízos nos quais não depositamos a mesma confiança. A diferença central é que os primeiros juízos são estáveis ao longo da vida de uma pessoa (por exemplo, eles não se alteram quando a pessoa altera suas crenças religiosas, políticas ou expande o seu conhecimento sobre o mundo) enquanto que os segundos são mais propensos a mudanças. Creio que essa divisão representa um claro ordenamento epistêmico das nossas convicções morais, e a atribuição de um papel normativo especial aos juízos fixos. Quando Rawls propõe a posição original como um procedimento para descobrir quais princípios de justiça nós devemos aceitar, ele afirma que nós devemos aceitá-la porque ela descreve ideias fundamentais implícitas (ideia de cidadão como livre e igual e de sociedade bem-ordenada) nos nossos juízos mais fixos, como os juízos de repúdio à escravidão e de tolerância religiosa. Por isso que o resultado da posição original é intuitivamente persuasivo: ele apenas estabelece as implicações daquilo que já aceitamos. Quando aceitamos os princípios de justiça que são resultado da posição original, e ajustamos o nosso senso de justiça a eles, o que nós realmente fazemos é utilizar ideias subjacentes aos nossos pontos mais fixos para orientar a revisão no restante do nosso sistema de crenças. Este ponto está defendendo a característica (1) do 
fundacionalismo moderado, com isso rejeitando a característica (1) do coerentismo: as crenças não-fundacionais (juízos menos fixos) são justificadas quando conformes às crenças fundacionais (juízos mais fixos).

Esse status epistêmico especial atribuído aos juízos mais fixos, e a consequente função normativa que eles desempenham no interior do método, apresenta um embaraço para uma leitura coerentista. No entanto, pode responder o coerentista, o fundacionalista está em uma situação pior, pois ele apresenta uma posição que contradiz o próprio nome do método. Para o ERA a justificação funciona por uma relação de coerência, reciprocidade ou equilíbrio entre crenças. Nós temos de buscar por ajustes entre as nossas crenças, e revisar umas a partir das outras, em um processo em que nenhuma crença está imune à revisão. Qualquer crença pode ser revisada se ela se mostrar incompatível com um conjunto coerente de crenças, do que se segue que não há uma crença não-inferencialmente justificada, isto é, uma crença cuja justificação não dependa do seu ajuste a um sistema coerente de crenças. Os nossos pontos fixos, embora mais fixos que outras crenças que sustentamos, sempre são provisórios, isto é, são vistos como injustificados se se mostrarem incoerentes com um conjunto coerente de crenças. Esse é o raciocínio empregado por Daniels contra a viabilidade de qualquer interpretação outra que a coerentista (DANIELS, 1996, p. 27-28).

O raciocínio de Daniels está comprometido com a seguinte proposição: se uma crença pode ser anulada se ela é incoerente com um sistema coerente de crenças, então a sua justificação é necessariamente inferencial. Essa proposição não parece, contudo, ser verdadeira. Rawls sempre usou a expressão “credibilidade inicial” para se referir aos juízos morais ponderados (RAWLS, 1975, p. 7). Essa é uma expressão largamente utilizada por Nelson Goodman (que Rawls considera o criador do equilíbrio reflexivo) para rejeitar o coerentismo. Goodman buscou discutir e refutar a posição segundo a qual não há espaço para dúvida entre a apresentação de um elemento na experiência e o meu juízo imediato a respeito do que é apresentado, de modo que a percepção poderia ser fonte de conhecimento direto, imediato e incorrigível. Essa pode ser lida com uma típica tese fundacionalista clássica. Contra ela Goodman afirma que qualquer enunciado, mesmo aqueles que dizem respeito à experiência imediata, pode ser rejeitado caso se mostre incompatível com outro enunciado que julgamos verdadeiro (GOODMAN, 1953, p. 161). Em suas palavras, um enunciado deve ser rejeitado se "a sua retenção resultar em um sistema que não satisfaz tanto quanto possível 
a totalidade de afirmações apresentadas por todos os enunciados relevantes" (GOODMAN, 1953, p. 163).

Não obstante afastando esse status de incorrigibilidade das crenças oriundas da experiência imediata, Goodman jamais negou que elas possuem uma função epistêmica especial dentro de um sistema de crenças. Se a coerência fosse suficiente para a justificação dessas crenças, pensou Goodman, nós não teríamos como arbitrar entre sistemas coerentes de crença conflitantes. Esse problema requer um critério epistêmico para arbitrar entre sistemas conflitantes que seja independente da coerência, de modo que a coerência deve ser necessária, mas não suficiente para a justificação. O critério suplementar que Goodman propõe é o da "credibilidade inicial": para um sistema de crença ser justificado, algumas de suas crenças, além de internamente coerentes, têm de possuir uma credibilidade inicial baseada em outros fatores que não a sua coerência com as outras crenças do sistema (GOODMAN, 1953, p. 163). Entre sistemas alternativos, o epistemicamente preferível é aquele que coerir com o maior número de crenças inicialmente credíveis, ou que implicar a rejeição do menor número delas. O ponto básico é que a credibilidade inicial é uma credibilidade epistêmica cuja fonte não é a coerência. Esse ponto afirma a característica (1) do fundacionalismo moderado ao mesmo tempo em que rejeita as características (1) e (2) do coerentismo holista ${ }^{12}$.

Goodman está reconhecendo uma distinção, explicitamente formulada por Audi, entre dependência negativa da coerência e dependência positiva. O fundacionalismo é negativamente dependente da coerência porque se houver incoerência (entre as próprias crenças básicas ou entre as crenças básicas e as não-básicas) não há justificação, mas ele não é positivamente dependente porque, diferentemente do coerentismo, não afirma que a coerência é a fonte da justificação (AUDI, 1993, p. 144). Em outros termos, para o coerentista a coerência é constitutiva da justificação ao passo que para o fundacionalista ela é uma característica consequente necessária da crença justificada. A única tese coerentista que um fundacionalista nega é a tese de que a coerência é uma base suficiente de justificação. A ideia de justificação por reciprocidade ou apoio mútuo, por exemplo, é um conceito chave em um framework fundacionalista porque permite explicar a corrigibilidade das crenças básicas.

Com a distinção entre dependência negativa e positiva da coerência é possível manter intacta a tese fundamental do ERA de que nenhum elemento é imune à revisão. Também é possível manter a inteligibilidade e a relevância das referências de Rawls ao holismo e à ideia de justificação por equilíbrio. Se uma crença (fundacional ou não) não for coerente com um conjunto de crenças, então ela não é justificada. A única qualificação a respeito do holismo 
que precisa ser feita a fim de acomodar essa leitura fundacionalista é a especificação de que a relação inferencial recíproca de crenças no interior do sistema não gera a justificação das crenças que são inicialmente credíveis.

Com essas distinções realizadas, creio que o fundacionalismo moderado se mostra congruente com todas as características "coerentistas" defendidas por Daniels e Rawls, como o endosso da atitude revisionista. Porém, por defender que nenhuma crença pode ser vista como epistemicamente privilegiada e que todas têm igual peso dentro de um sistema coerente de crenças, a interpretação coerentista não consegue acomodar a distinção entre juízos mais fixos e menos fixos, com isso não fazendo justiça ao status epistêmico especial dos primeiros ${ }^{13}$. Uma interpretação fundacionalista, por sua vez, está em posição de reconhecer essa distinção, o que a torna preferível como uma interpretação do método do equilíbrio reflexivo.

\section{A ideia de credibilidade inicial}

Então, como nós devemos entender a credibilidade epistêmica inicial desfrutada pelos pontos fixos provisórios? Nesta seção conclusiva eu pretendo apenas sugerir os contornos gerais de uma resposta para essa pergunta

Rawls afirma que cada juízo moral ponderado tem um certo nível de credibilidade inicial para nós. Essa generalização deve ser corrigida por uma leitura fundacionalista. Devemos utilizar a expressão juízos morais ponderados iniciais para designar aqueles que possuem credibilidade inicial ("mais fixos”) e que são justificados não-inferencialmente. Por outro lado, devemos denominar de juízos morais ponderados simpliciter aqueles alcançados em ERA, isto é, após o indivíduo refletir sobre o seu senso de justiça orientado pelos seus juízos morais ponderados iniciais. A credibilidade dos juízos simpliciter tem de ser derivada dos juízos iniciais, e a destes últimos tem de ser, obrigatoriamente, não-derivativa. A credibilidade dos juízos simpliciter é derivativa no seguinte sentido: quando eles são questionados, $S$ tende a citar os juízos iniciais para justificá-los. Quando os juízos iniciais são questionados, $S$ tem de dizer que "ele sente" que aquela é a resposta correta e que não há nada mais para ser dito.

Alguns filósofos acreditam que esse tipo de construção aproxima o ERA do intuicionismo clássico de Moore ou Ross, o que seria trair o espírito do método e aproximá-lo da posição epistemológica contra a qual ele foi originalmente criado para se contrapor. Porém, 
nós podemos entender a credibilidade epistêmica dos juízos morais ponderados iniciais como fundada no próprio ato doxástico de afirmá-los com um alto grau de comprometimento. Como exposto por Scheffler, a ideia de credibilidade inicial remete a uma perspectiva de primeira pessoa: classificar uma sentença de acordo com a sua credibilidade inicial é classificá-la, ao mesmo tempo, de acordo com o comprometimento inicial com que ela é sustentada (SCHEFFLER, 1954, p. 187). A credibilidade de uma sentença é igual ao comprometimento (commitment) com que $S$ a sustenta. Para Scheffler, $S$ está comprometido com sentenças "em todos os níveis de generalidade", de modo que o seu objetivo deve ser o de harmonizar todos os seus comprometimentos selecionando, a cada momento, um conjunto deles que pode servir como um padrão de justificação para julgar sistemas alternativos igualmente coerentes, porém incompatíveis entre si.

A ideia de credibilidade entendida em termos de comprometimento remete ao que Foley defende como um fundacionalismo subjetivista. Para Foley uma crença p é básica para $S$ se e somente se é incontroverso para $S$ aceitar p. $S$ tem de sustentar p com mais confiança com que sustenta outras crenças que poderia utilizar para argumentar contra $p$, e $p$ tem de ser tal que $S$, em reflexão, tem de acreditar que quando sustenta p a sua crença em p é verdadeira. Essa definição de crença básica acentua a propriedade de ser "psicologicamente convincente" para o indivíduo que a sustenta (FOLEY, 1987, p. 68-71). Note que o que conta como básico não é determinado em função de qualquer fato ou critério de correção de crenças externo ao indivíduo. Se uma proposição não é incontroversa para $S$, então nenhuma garantia de verdade ou fato a torna básica. Se $S$ não estiver ciente de que a sua crença é verdadeira ou que ela descreve algum fato moral, essa crença não será básica porque $S$ terá bons argumentos contra ela. A propriedade de ser básica seria então simplesmente uma questão de nível de comprometimento, e a credibilidade inicial de uma dada crença remete ao estado mental que ela expressa. 


\section{Notas:}

${ }^{1}$ Doutorando no Programa de Pós-Graduação em Filosofia da Universidade do Vale do Rio dos Sinos (UNISINOS), São Leopoldo, R.S., Brasil. E-mail: tiaraju.andreazza@gmail.com

2 "Wide Reflective Equilibrium keeps us from taking considered moral judgments at face value, however much they may be treated as starting points in our theory construction. Rather, they are always subjected to exhaustive review and are 'tested', as are the moral principles, against a relevant body of theory. At every point we are forced to assess their acceptability relative to theories that incorporate them and relative to alternative theories incorporating different considered moral judgments" (Daniels, 1996, p. 28). O mesmo aspecto é destacado por Rawls (1975, p. 7-10), Scanlon (2003, p. 149), Brink (1989, p. 130-133), para citar alguns.

${ }^{3}$ Uma crítica comum ao método é a de que ele confunde justificação com aceitação (HABERMAS, 1995, p. 122). Mas o equilíbrio reflexivo não pretende descrever fatos brutos, como os fatos sobre o que as pessoas aceitam como justificado. O que ele descreve são estados normativos: o que as pessoas deveriam aceitar como justificado. O que as pessoas deveriam aceitar como justificado é o que elas aceitariam se fossem apropriadamente reflexivas, e o que elas aceitariam nessas condições não é sequer dependente do que elas efetivamente aceitam.

\footnotetext{
${ }^{4}$ Nem todos compartilham dessa interpretação. Habermas interpreta o equilíbrio reflexivo como um método na terceira pessoa que é alcançado no momento em que o filósofo apresenta a um indivíduo uma reconstrução das suas intuições que ele não pode rejeitar com boas razões (HABERMAS, 1995, p. 120). Mais recentemente essa interpretação foi proposta por Mikhail (2011, p. 289). Para uma interpretação de que o equilíbrio reflexivo deve ser entendido como um método de reflexão em primeira pessoa, ver Scanlon (2003, p. 144-148).
}

${ }^{5}$ Essa maneira de apresentar o método através de passos ou estágios é adotada por Scanlon. Ele identifica três estágios: (i) identificar os juízos morais ponderados, (ii) encontrar princípios que expliquem esses juízos e (iii) busca por ajuste mútuo entre princípios descobertos em (ii) e juízos identificados em (i) (2003, p. 140-141; 2014, p. 76-78).

${ }^{6}$ Daniels (1996), Brink (1989), Thomas (2006), Audi (2004, p. 47-79), Scanlon (2014, p. 84).

${ }^{7}$ Rawls (1993; 1999), DePaul (1993), Foley (2004, 43-44), Sosa (1991, 57-266), Smith (1994, 159-160).

${ }^{8}$ Usualmente é reconhecida uma diferença entre equilíbrio reflexivo estreito (narrow) e amplo. Daniels define o segundo como um método para produzir coerência entre (a) juízos morais ponderados, (b) princípios e (c) teorias de fundo (background theories). O indivíduo procuraria por princípios que explicariam os seus juízos, e então testaria a validade desses princípios a partir da consideração de certas teorias de fundo, como teorias morais e os seus conceitos filosóficos mais importantes (DANIELS, 1996, p. 49-50). A versão estreita contaria apenas com (a) e (b). O problema com essa distinção entre duas versões é que ela é apenas significativa se a plausibilidade de (c) for determinada independentemente de (a). Daniels tentou defender que o conjunto de juízos morais ponderados que justifica (c) é relevantemente distinto daquele caracterizado por (b) (DANIELS, 1996, p. 22-26). Conforme defendido por outros, os argumentos apresentados por Daniels em favor dessa tese são inconvincentes (HOLMGREN, 1989). Se se assume que a validade dos juízos morais ponderados, bem como de quaisquer considerações que os expliquem, seja (b) ou (c), é determinado em reflexão, como Daniels endossa, então qualquer noção de suporte independente deixa de ser viável. Daniels estava pressionado pelas acusações de que o ERA é conservador (e que ele poderia proteger preconceitos morais como justificados) por depender demasiadamente dos juízos morais ponderados (BRANDT, 1998, p. 20). Acredito que o objetivo do ERA é apontar para um conjunto de crenças que é o mais justificado para um indivíduo, dado o que mais ele acredita. Ele pode autorizar como justificados certos preconceitos morais porque o que muitas pessoas têm mais razões para aceitar como justificado, dadas as circunstâncias dos seus pontos de vista, são preconceitos morais. Mas dizer para um nazista ou mafioso (para usar duas figuras populares nesse tipo de conversação filosófica) que as suas crenças nazistas ou mafiosas são justificadas, dado o que mais ele acredita, é uma forma de enfatizar o quão profundamente vicioso é o que ele demais acredita. Daniels parece ter pensado que fora o ERA não há outros critérios de justificação, nenhuma outra base para criticar moral ou epistemologicamente as crenças de um 
indivíduo. O proponente do ERA não precisa e nem deve compartilhar dessa assunção, e uma vez que ela não é aceita se torna menos embaraçoso aceitar que alguém pode estar justificado em sustentar proposições morais que são claramente reprováveis.

${ }^{9}$ Não há convergência na resposta a essa pergunta. A leitura coerentista é defendida, dentre outros, por Daniels (1996), Brink (1989), Sayre-McCord (2007) e, possivelmente, Rawls (2001, p. 31), enquanto que a leitura fundacionalista é proposta por Audi (2004, p. 224), Ebertz (1993), Timmons (1999) e Thomas (2006), para mencioanr alguns.

${ }^{10}$ Essa definição extrai elementos de duas definições oferecidas por Audi (1993, p. 134; 2011, p. 233).

${ }^{11}$ A definição que o próprio BonJour oferece da sua posição é a seguinte: "uma visão de acordo com a qual (1) não há crenças fundacionais ou básicas e (2) a base primária para a justificação empírica é o fato de que tais crenças se ajustam conjuntamente e apoiam-se umas nas outras, assim formando um sistema coerente de crenças" (BONJOUR, 2003, p. 42).

${ }^{12}$ Audi utiliza o ERA na sua tentativa de revitalizar o intuicionismo de Ross (AUDI, 2011, p. 49-51).

${ }^{13}$ Contra uma leitura fundacionalista, alguém poderia recorrer ao argumento de Brink em favor de uma interpretação coerentista do ERA. O argumento de Brink diz que os juízos morais ponderados não são nãoinferencialmente justificados porque eles são justificados pelo fato de que são ponderados, o que significa dizer que eles são justificados porque são coerentes com crenças de segunda-ordem sobre por que juízos ponderados são conducentes à verdade e ao conhecimento (BRINK, 1989, p. 134-135). Um argumento que apela para crenças de segunda-ordem confunde inadequadamente níveis diferentes de justificação. Eu posso estar justificado em sustentar que $\mathrm{p}$ sem ser capaz de mostrar a justificação de $\mathrm{p}$, ou posso estar justificado em sustentar que $\mathrm{p}$ mesmo se $\mathrm{p}$ é falsa. $\mathrm{O}$ argumento de Brink implica que eu não posso justificadamente aceitar uma crença baseada na experiência imediata ao menos que eu tenha uma teoria para explicar a confiabilidade do meu aparato perceptivo. Para retomar: a questão é saber qual a estrutura de crenças de quem sustenta crenças justificadamente. O ponto de vista relevante é o de primeira pessoa, no qual crenças de segunda-ordem, do tipo requerido para o argumento de Brink funcionar, não fazem parte. 


\section{Referências:}

AUDI, Robert. A Contemporary Introduction to the Theory of Knowledge. Third Edition. New York: Routledge, 2011.

. The Good in the Right: A Theory of Intuition and Intrinsic Value. Princeton: Princeton University Press, 2004.

. The Structure of Justification. New York: Cambridge University Press, 1993.

BONJOUR, Laurence; SOSA, Ernest. Epistemic Justification: Internalism vs Externalism, Foundations vs Virtues. Oxford: Blackwell Publishing, 2003.

BRANDT, Richard. A Theory of the Good and the Right. New York: Prometheus Books, 1998.

BRINK, David. Moral Realism and the Foundations of Ethics. New York: Cambridge University Press, 1989.

DANIELS, Norman. Justice and Justification: Reflective Equilibrium in Theory and Practice. Cambridge: Cambridge University Press, 1996.

EBERTZ, Roger. Is Reflective Equilibrium a Coherentist Model?. Canadian Journal of Philosophy, v. 23, n. 2, p. 193-214, 1993.

FOLEY, Richard. A Theory of Epistemic Rationality. Cambridge, Harvard University Press, 1987.

GOODMAN, Nelson. Sense and Certainty. The Philosophical Review, v. 61, n. 2, p.160$167,1952$.

HABERMAS, Jurgen. Reconciliation through the public use of reason: Remarks on John Rawls' Political Liberalism. The Journal of Philosophy, v. 92, n. 3, p. 109-131, 1995.

HOLMGREN, Margaret. The Wide and Narrow of Reflective Equilibrium. Canadian Journal of Philosophy, v. 19, n. 1, p. 43-60, 1989.

MIKHAIL, John. Elements of Moral Cognition: Rawls' Linguistic Analogy and the Cognitive Science of Moral and Legal Judgment. Cambridge: Cambridge University Press, 2011.

RAWLS, John. A Theory of Justice. Revised Edition. Cambridge: Harvard University Press, 1999.

Justice as Fairness: A Restatement. Cambridge: Harvard University Press, 2001. 
Outline of a Decision Procedure for Ethics. The Philosophical Review, v. 60, n. 2, p. 177-197, 1951.

1993

Political Liberalism. Expanded Edition. New York: Columbia University Press,

The Independence of Moral Theory. Proceedings and Addresses of the American Philosophical Association, v. 48, p. 5-22, 1975.

SAYRE-MCCORD, Geoffrey. Coherentism and the Justification of Moral Beliefs. In: SHAFER-LANDAU, Russ. Ethical Theory. Oxford: Blackwell Publishing, 2007. p. 123139.

SCANLON, Thomas. Being Realistic About Reasons. Oxford: Oxford University Press, 2014.

. Rawls on Justification. In: FREEMAN, Samuel (Ed.). The Cambridge Companion to Rawls. Cambridge: Cambridge University Press, 2003. p. 139-168.

SCHEFFLER, Israel. On Justification and Commitment. The Journal of Philosophy, v. 51, n. 6, p.180-190, 1954.

SMITH, Michael. The Moral Problem. Oxford: Blackwell Publishing, 1994.

SOSA, Ernest. Knowledge in Perspective: Selected Essays in Epistemology. Cambridge: Cambridge University Press, 1991.

TIMMONS, Mark. Morality without Foundations: A Defense of Ethical Contextualism. Oxford: Oxford University Press, 1999.

THOMAS, Alan. Value and Context: The Nature of Moral and Political Knowledge. Oxford: Oxford University Press, 2006. 